\title{
EFFECTS OF NISOLDIPINE ON RECOVERY OF CORONARY BLOOD FLOW, SARCOPLASMIC RETICULUM FUNCTION AND OTHER BIOCHEMICAL PARAMETERS IN POST-ISCHAEMIC PORCINE MYOCARDIUM
}

\author{
Loes M. A. Sassen, ${ }^{*}$ Karel Bezstarosti, $†$ Pieter D. Verdouw* \\ and JOS M. J. LAMERS $\dagger \ddagger$ \\ *Laboratory for Experimental Cardiology, Thoraxcenter and + Department of Biochemistry, Erasmus \\ University Rotterdam, P.O. Box 1738, 3000 DR Rotterdam, The Netherlands
}

(Received 17 April 1990; accepted 10 August 1990)

\begin{abstract}
The effects of nisoldipine $(0.1 \mu \mathrm{g} / \mathrm{kg} / \mathrm{min} ; n=9)$ or its solvent $(n=9)$ were studied in pigs, in which left anterior descending coronary artery (LADCA) blood fiow in both groups was reduced to $20 \%$ of baseline for $60 \mathrm{~min}$ and reperfused for $2 \mathrm{hr}$. Infusions were started at $30 \mathrm{~min}$ of ischaemia and lasted throughout reperfusion. In both groups, flow reduction abolished regional contractile function and caused similar decreases in the level of creatine phosphate (CP; by $70 \%)$ and the energy charge (from 0.91 to 0.69 ), mean arterial blood pressure (by $25 \%$ ), $L V \mathrm{~d} P / \mathrm{d} t_{\max }$ (by $30 \%$ ) and cardiac output (by $30 \%$ ). During ischaemia LADCA blood flow slightly increased (from $14 \pm 8$ to $24 \pm 6 \mathrm{~mL} / \mathrm{min}$ ) $100 \mathrm{~g} ; \mathrm{P}<0.05$ ) in the nisoldipine-treated animals, resulting in an increase in $\mathrm{CP}$ to $91 \pm 24 \%$ of baseline and preventing further decreases in energy charge, as observed in the solvent-treated animals. After $2 \mathrm{hr}$ of reperfusion in neither group return of contractile function of the post-ischaemic myocardium was observed. Post-ischaemic blood flow in the nisoldipine-treated pigs increased from $24 \pm 6 \mathrm{~mL} / \mathrm{min} / 100 \mathrm{~g}$ to $76 \pm 14 \mathrm{~mL} / \mathrm{min} / 100 \mathrm{~g}$ and from $19 \pm 6 \mathrm{~mL} / \mathrm{min} / 100 \mathrm{~g}$ to $41 \pm 6 \mathrm{~mL} / \mathrm{min} / 100 \mathrm{~g}$ in the solvent-treated animals $(P<0.05)$ after $2 \mathrm{hr}$ of reperfusion. Myocardial work was significantly higher in the nisoldipinetreated animals $(111 \pm 15 \mathrm{mmHg} . \mathrm{L} / \mathrm{min}$ as compared to $69 \pm 14 \mathrm{mmHg} . \mathrm{L} / \mathrm{min}$ in the solvent-treated pigs after $2 \mathrm{hr}$ of ischaemia). The energy charge of the post-ischaemic myocardium was similar for both groups $(0.84 \pm 0.02$ for the nisoldipine-treated and $0.83 \pm 0.03$ for the solvent-treated animals). The rate of sarcoplasmic reticular $\mathrm{Ca}^{2+}$ uptake of the non-ischaemic segment of the nisoldipine-treated animals was $61 \%$ higher $(\mathrm{P}<0.05)$ than that of the solvent-treated animals. In the post-ischaemic myocardium similar rates of $\mathrm{Ca}^{2+}$ uptake were found in both groups, but the activities were markedly lower as compared to the non-ischaemic myocardium. It is concluded that nisoldipine increases blood flow during reperfusion, which may have been caused by coronary vasodilatation. However, attenuation of the "no-reflow" phenomenon also contributed, since more rapid rephosphorylation of ADP leading to an increase in CP during ischaemia may have preserved jeopardized cells. Moreover, nisoldipine increases the sarcoplasmic reticular $\mathrm{Ca}^{2+}$ pump activity independent of ischaemia, which may have contributed in reducing the $\mathrm{Ca}^{2+}$ overload.
\end{abstract}

The rapid and uncontrolled increase in cytosolic $\mathrm{Ca}^{2+}$ that occurs upon reperfusion of ischaemic myocardial tissue is believed to play a central role in the subsequent loss in cell viability. The $\mathrm{Ca}^{2+}$ overload triggers a chain of destructive events. Activation of $\mathrm{Ca}^{2+}$-dependent reactions such as ATPases, proteases and phospholipases result in energy waste and membrane disruption. The cytosolic free $\mathrm{Ca}^{2+}$ concentration can increase by entrance via the $\mathrm{Na}^{+}: \mathrm{Ca}^{2+}$ antiporter [1], via

¥ Address for correspondence: J. M. J. Lamers, PhD, Department of Biochemistry I, Faculty of Medicine and Health Sciences, Erasmus University, Rotterdam, P.O. Box 1738, 3000 DR Rotterdam, The Netherlands.

$\S$ Abbreviations: SR, sarcoplasmic reticulum; CP, creatine phosphate; ATP, adenosine-5'-triphosphate; ADP, adenosine-5' -diphosphate; HPLC, high performance liquid chromatography; SDS, sodium dodecylsulphate; LADCA, left anterior descending coronary artery; $L V \mathrm{~d} P / \mathrm{d} t_{\max }$, maximum rate of rise of left ventricular blood pressure; $E D T$, end-diastolic wall thickness; $E S T$, end-systolic wall thickness; SWT, systolic wall thickening; PSWT, post-systolic wall thickening; $\max T$, maximal wall thickness. receptor- and voltage-operated $\mathrm{Ca}^{2+}$ channels and, as the cell membrane disintegrates via passive diffusion [2]. The loss in ability of the sarcolemma and sarcoplasmic reticulum (SR\&) to remove $\mathrm{Ca}^{2+}$ from the cytosol could also contribute to cytosolic $\mathrm{Ca}^{2+}$ overload. Ischaemia causes a reduction in active $\mathrm{Ca}^{2+}$ transport rate of sarcoplasmic reticulum [3] and sarcolemma [4]. $\mathrm{Ca}^{2+}$ entry blockers are specific blockers of the voltage-operated $\mathrm{Ca}^{2+}$ channels [5] and therefore have the potential to protect the myocardium against $\mathrm{Ca}^{2+}$ overload [6]. Moreover, some dihydropyridines (nitrendipine and felodipine) have been shown to directly stimulate the in vitro $\mathrm{Ca}^{2+}$ uptake rate of canine sarcoplasmic reticulum, which may present another potential action site to prevent myocardial $\mathrm{Ca}^{2+}$ overload [7].

The activity of the sarcoplasmic reticulum $\mathrm{Ca}^{2+}$ pump is modulated by phospholamban phosphorylation $[8,9]$. Experiments conducted with intact hearts indicate that cyclic AMP- and $\mathrm{Ca}^{2+}$. induced phosphorylation of phospholamban is involved in the $\beta$-adrenergic activation of the calcium pump of the SR [10]. We obtained evidence that the ischaemia-induced inactivation of the calcium pump 
is a consequence of the altered characteristics of phospholamban and may be of value as an early marker of long-term recovery of function following reperfusion of ischaemic myocardium [3].

In addition to their vasodilatory potential, leading to increases in blood flow to the area at risk and sparing of energy, $\mathrm{Ca}^{2+}$ entry blockers can also preserve myocardium by avoiding the loss of adenosine precursors [11], protect the vascular endothelial cells independent of vasodilatation [12], beneficially interact with the sarcolemma membrane [13] and mitochondria [14] of the myocardial cell. By protecting the myocardium via these mechanisms, $\mathrm{Ca}^{2+}$ antagonists may also indirectly prevent the reduction in the $\mathrm{Ca}^{2+}$ uptake and phospholamban phosphorylation of sarcoplasmic reticulum of postischaemic myocardium.

The present study was conducted to investigate the effects of nisoldipine, given $30 \mathrm{~min}$ prior to and throughout reperfusion, on the $\mathrm{Ca}^{2+}$ transport activity and in vitro ${ }^{32} \mathrm{P}$ incorporation into phospholamban of $\mathrm{SR}$, isolated from large transmural myocardial segments of pigs subjected to $1 \mathrm{hr}$ of ischaemia followed by $2 \mathrm{hr}$ of reperfusion. In view of the relative lack of data on the effects of nisoldipine on energy metabolism in an in vivo model, other biochemical parameters such as the energy charge and levels of creatine phosphate (CP) were measured in small transmural myocardial biopsies collected during ischaemia and reperfusion. Additionally, the effects of the drug on systemic haemodynamics, regional contractile function and coronary blood flow were investigated.

\section{MATERIALS AND METHODS}

General. After an overnight fast cross-bred Landrace $\times$ Yorkshire pigs of either sex $(\mathrm{N}=18$, $25-42 \mathrm{~kg}$ ) were sedated with $120 \mathrm{mg}$ azaperone (Janssen Pharmaceutica, Beerse, Belgium) i.m., anaesthetized with $150 \mathrm{mg}$ metomidate (Janssen Pharmaceutica), i.v, and intubated for artificial ventilation with a mixture of oxygen and nitrous oxide $(1: 2)$. Respiratory rate and tidal volume were adjusted to keep arterial blood gases within the normal range: $\mathrm{pH}$ between 7.37 and $7.49 ; \mathrm{pCO}_{2}$ between 34 and $48 \mathrm{mmHg} ; \mathrm{pO}_{2}$ between 120 and $180 \mathrm{mmHg}$. A catheter was positioned into the superior caval vein for the administration of $160 \mathrm{mg}$ / kg $\alpha$-chloralose (Merck, Darmstadt, F.R.G.) followed by an infusion of $5 \mathrm{mg} / \mathrm{kg} / \mathrm{hr}$ pentobarbitone sodium (Sanofi, Paris, France) and for the administration of the muscle relaxant pancuronium bromide ( $4 \mathrm{mg}$ ) prior to thoracotomy. Haemaccel (Behringwerke A.G., Marburg, F.R.G.) was administered to replace the blood, withdrawn during sampling (see below). An 8F micromanometertipped catheter (Millar, Houston, TX, U.S.A.) was inserted into the left ventricle by way of the left carotid artery, for the measurement of left ventricular blood pressure and its first derivative $(L V \mathrm{~d} P / \mathrm{d} t)$. Catheters were also inserted into the aorta, for measurement of central aortic blood pressure (50 AD pressure transducer, Spectramed, Bilthoven, The Netherlands), the collection of blood samples for the determination of blood gases and for the withdrawal of reference samples necessary for calibration of the radioactive microsphere flow measurements. After thoracotomy, an electromagnetic flow probe (Skalar, Delft, The Netherlands) was placed around the ascending aorta for the measurement of aortic blood flow. The left anterior descending coronary artery (LADCA) was dissected free just distal from its first diagonal branch and an inflatable balloon (R. E. Jones, Silver Spring, MD, U.S.A.) was placed around the LADCA and connected to a $1 \mathrm{~mL}$ syringe (Hamilton Bonaduz, Bonaduz, Switzerland) driven by a micrometer (Hamilton Co., Reno, NV, U.S.A.). The vein accompanying the LADCA was cannulated for the withdrawal of blood samples for the determination of coronary venous blood gases.

Regional blood flow. To determine regional blood flows the left atrial appendage was catheterized for the injection of a batch of $1-2 \times 10^{6}$ radioactive microspheres, $15 \pm 1$ (SD) $\mu \mathrm{m}$ in diameter (NEN Company, Dreieich, F.R.G.), labelled with either ${ }^{95} \mathrm{Nb},{ }^{103} \mathrm{Ru},{ }^{113} \mathrm{Sn},{ }^{46} \mathrm{Sc}$ or ${ }^{141} \mathrm{Ce}$. Full details of the procedures and the calculation of flow data using the reference sample technique have been reported earlier $[15,16]$.

Regional myocardial function. Regional myocardial function was estimated from recordings of myocardial wall thickness obtained with a $5 \mathrm{MHz}$ ultrasonic transducer (Krautkamer-Branson, Lewistown. PA, U.S.A.) sutured onto a part of the epicardial surface perfused by the LADCA. From the tracings end-diastolic ( $E D T)$, end-systolic (EST) and maximal post-systolic (max $T$ ) wall thickness were measured. Systolic wall thickening $(S W T, \%)$ was calculated as $100 \times(E S T-E D T) / E D T$, while post-systolic wall thickening (PSWT, \%) was defined as $100 \times(\max T-E S T) / E D T$.

Experimental protocol. After systemic haemodynamics had been stable for at least $30 \mathrm{~min}$ following completion of the instrumentation, baseline values of systemic haemodynamics, regional myocardial function and arterial and coronary venous blood gases were obtained while a batch of microspheres was injected for the measurement of distribution of myocardial blood flow. Furthermore, transmural needle biopsies (processed as described below) were taken from the myocardium nourished by the distal part of the LADCA and from a segment of the anterior wall of the heart, which was not supplied by the LADCA. In all pigs the flow in the LADCA was then gradually reduced by slowly inflating the balloon, until complete loss of regional contractile function. After $30 \mathrm{~min}$ of ischaemia, the measurements of systemic haemodynamics and regional blood flows were repeated and a transmural biopsy was taken from the ischaemic area. In nine animals an infusion of nisoldipine $(0.1 \mu \mathrm{g} / \mathrm{kg} / \mathrm{min})$ was started and in the other animals solvent was administered at a similar infusion rate $(1 \mathrm{~mL} / \mathrm{min})$. If ventricular fibrillation occurred the animal was promptly (within $30 \mathrm{sec}$ ) defibrillated with DCcountershock. After $60 \mathrm{~min}$, when all measurements had been repeated and biopsies were obtained from both the ischaemic and the non-ischaemic area, the balloon was deflated. Two hours later, the last 
haemodynamic measurements were taken and biopsies were collected. The heart was then excised and immediately cooled on ice and transmural myocardial samples $(5-7 \mathrm{~g})$ were obtained from the post-ischaemic segment and from the posterior wall of the heart (non-ischaemic segment). The segments were homogenized for isolation of SR membrane vesicles (see below). Furthermore, the radioactive label present in the pellet after the first centrifugation step $(10,000 \mathrm{~g}, 20 \mathrm{~min})$ for $\mathrm{SR}$ isolation was counted in order to obtain myocardial blood flow data.

Adenine nucleotides, creatine phosphate and creatine. The transmural myocardial biopsies, taken with a Tru-Cut needle (Travenol Laboratories Inc., Deerfield, IL, U.S.A.) from the ischaemic area and the adjacent non-ischaemic area were dipped into $0.9 \% \mathrm{NaCl}$ of $0^{\circ}$ to remove adherent blood, and immediately (within $10 \mathrm{sec}$ ) frozen in liquid nitrogen. The biopsies were stored at $-80^{\circ}$ until analysis. The biopsies $(5-20 \mathrm{mg})$ were homogenized in $0.5 \mathrm{~mL}$ $0.42 \mathrm{M} \mathrm{HClO}_{4}$ at liquid nitrogen temperature with the Braun micro-dismembrator (B. Braun, Melsungen, F.R.G.), thawed, shaken and centrifuged. After neutralization of the supernatant the adenine nucleotides, $\mathrm{CP}$ and creatine were separated and the concentrations estimated with an isocratic ionpairing high performance liquid chromatography (HPLC) [17], except that $175 \mathrm{mM}$ potassium phosphate, $2.3 \mathrm{mM}$ tetrabutylammonium hydrogensulfate, $2.5 \%$ acetonitrile, $\mathrm{pH} 6.25$ was used as a running buffer. With this HPLC method we also checked the purity of the $\left[\gamma_{-}{ }^{32} \mathrm{P}\right] \mathrm{ATP}$ used in the phospholamban phosphorylation assays.

Isolation of sarcoplasmic reticulum. The transmural myocardial tissue samples were homogenized three times during $10 \mathrm{sec}$ in 4 volumes of $10 \mathrm{mM} \mathrm{NaHCO}$, pH 7.0 at $0^{\circ}$ with a Polytron PT 10 (Kinematica $\mathrm{GmbH}$, Luzern, Switzerland). The SR was isolated as described [3]. Immediately after isolation, the SR suspension was frozen in liquid nitrogen and stored at $-80^{\circ}$ until analysis of $\mathrm{Ca}^{2+}$ uptake and phospholamban phosphorylation activities.

Phosphorylation of phospholamban and $\mathrm{Ca}^{2+}$ uptake activity. The cyclic AMP-dependent phosphorylation of SR vesicles $(5-10 \mu \mathrm{g}$ protein) was determined as described [3] with $5 \mu \mathrm{M}$ cyclic AMP to activate the endogenous protein kinase and 300 units/mL exogenous catalytic subunit of cyclic AMPdependent protein kinase (Sigma Chemical Co, St Louis, MO, U.S.A.). The samples were preincubated for $2 \mathrm{~min}$ at $25^{\circ}$ and the phosphorylation reaction was started by the addition of $200 \mu \mathrm{M}$ (final concentration) $\left[\gamma-{ }^{32} \mathrm{P}\right]$ ATP $(150 \mathrm{TBq} / \mathrm{mol})$. After $5 \mathrm{~min}$ the reaction was stopped with a mixture of sodium dodecylsulphate (SDS), $\beta$-mercaptethanol and glycerol $[3,18]$. The samples were then heated at $95^{\circ}$ to dissociate phospholamban into monomers, and subjected to SDS-polyacrylamide gel electrophoresis [18]. Phosphorylated phospholamban was located on dried gels by autoradiography and ${ }^{32} \mathrm{P}$ content in the pieces, excised from the gel, was estimated by liquid scintillation counting. $\mathrm{Ca}^{2+}$ uptake activity was measured by incubation of SR with $50 \mu \mathrm{M}{ }^{45} \mathrm{Ca}$ in the presence of $1 \mathrm{mM}$ ATP [3]. After the incubation the ${ }^{45} \mathrm{Ca}$-containing SR vesicles were filtered through Millipore filters $(0.45 \mu \mathrm{m})$. The
${ }^{45} \mathrm{Ca}$ content of the SR vesicles remaining on the filters was estimated by liquid scintillation counting [3]. $\mathrm{Ca}^{2+}$ uptake activity in blank reactions, obtained by omitting ATP from the reaction mixture, were subtracted.

Protein. The protein content of SR was estimated with the method of Lowry et al. [19]. In the needle biopsies, protein was estimated by a procedure other than in the crude pellet obtained after centrifugation of the homogenate acidified with $\mathrm{HClO}_{4}$. After dissolution in $0.1 \mathrm{M} \mathrm{KOH}$, protein was estimated with the Coomassie Brilliant Blue assay [20] ohtained from Bio-Rad (Bio-Rad Laboratories, Munich, F.R.G.). For both methods bovine serum albumin was used as the standard.

Drugs. Nisoldipine (Bayer A.G., Wuppertal, F.R.G.) was dissolved in a mixture of polyethylene glycol 400, glycerol and distilled water. The nisoldipine solution $(0.1 \mathrm{mg} / \mathrm{mL})$ was diluted with $0.9 \%(\mathrm{w} / \mathrm{v}) \mathrm{NaCl}$ immediately before use. Preparation of the solution and administration of nisoldipine occurred while the drug was protected from light.

Statistical analysis. All data have been presented as means $\pm \mathrm{SE}$. The significance of the changes produced by the LADCA flow reduction in the animals was evaluated by Duncan's new multiple range test once an analysis of variance had revealed that the samples represented different populations. The significance of the nisoldipine-induced changes was determined by comparing these changes with those observed in the solvent-treated animals at corresponding times. Statistical significance was accepted for $\mathrm{P}<0.05$.

\section{RESULTS}

\section{Ventricular arrhythmias}

In both groups seven out of nine animals $(78 \%)$ encountered an episode of ventricular fibrillation during the ischaemic period. All animals were defibrillated within $25 \mathrm{sec}$ and resumed prefibrillation values. Ventricular fibrillation was not observed during reperfusion in any animal.

\section{Systemic haemodynamics}

During the first 30 min of LADCA flow reduction in the solvent-treated animals mean arterial blood pressure, cardiac output, stroke volume and $L V \mathrm{~d} P /$ $\mathrm{d} t_{\max }$ had decreased $(\mathrm{P}<0.05)$ by $23,30,36$ and $32 \%$, respectively, left ventricular end diastolic pressure increased from 8 to $13 \mathrm{mmHg}(\mathrm{P}<0.05)$, while heart rate was not affected (Table 1). During the $2 \mathrm{hr}$ of reperfusion there was a further decline in mean arterial blood pressure (to $59 \%$ of baseline), $L V \mathrm{~d} P / \mathrm{d} t_{\max }$ (to $54 \%$ of baseline), cardiac output (to $52 \%$ of baseline) and stroke volume (to $56 \%$ of baseline), while left ventricular end diastolic pressure further increased to $14 \pm 2 \mathrm{mmHg}$. Vasoconstriction (increase in systemic vascular resistance to $35 \%$ above baseline) prevented a more severe fall in mean arterial blood pressure (Table 1). During ischaemia there were similar decreases in mean arterial blood pressure, cardiac output, stroke volume and $L V \mathrm{~d} P / \mathrm{d} t_{\max }$ in the nisoldipine-treated animals (Table 1 ). During reperfusion cardiac output 
Table 1. Systemic haemodynamics in solvent-treated and nisoldipine-treated open-chest anaesthetized pigs at baseline (BL), 30 and $60 \mathrm{~min}$ of ischaemia (I) and $120 \mathrm{~min}$ of reperfusion (R). Nisoldipine

$(0.1 \mu \mathrm{g} / \mathrm{kg} / \mathrm{min})$ was started at $30 \mathrm{~min}$ of ischaemia and lasted throughout reperfusion

\begin{tabular}{llcccc}
\hline & & BL & $30 \mathrm{I}$ & $60 \mathrm{I}$ & $120 \mathrm{R}$ \\
\hline$M A P$ & SOL & $97 \pm 5$ & $75 \pm 5^{*}$ & $72 \pm 3^{*}$ & $57 \pm 4^{*}$ \\
& NIS & $90 \pm 4$ & $66 \pm 5^{*}$ & $65 \pm 3^{*}$ & $65 \pm 6^{*} \pm \S$ \\
& SOL & $2.3 \pm 0.1$ & $1.6 \pm 0.1^{*}$ & $1.6 \pm 0.1^{*}$ & $1.2 \pm 0.2^{*}$ \\
$H R$ & NIS & $2.5 \pm 0.2$ & $1.8 \pm 0.1^{*}$ & $1.8 \pm 0.1^{*}$ & $1.6 \pm 0.2^{*} \S$ \\
& SOL & $94 \pm 5$ & $98 \pm 4$ & $95 \pm 7$ & $88 \pm 8$ \\
$L V \mathrm{~d} P / \mathrm{d} t_{\max }$ & NIS & $95 \pm 4$ & $100 \pm 6$ & $97 \pm 4$ & $103 \pm 8$ \\
& SOL & $2590 \pm 130$ & $1760 \pm 120^{*}$ & $1850 \pm 140^{*}$ & $1390 \pm 230^{*}$ \\
$L V E D P$ & NIS & $2390 \pm 160$ & $1690 \pm 90^{*}$ & $1550 \pm 120^{*}$ & $1900 \pm 240^{*} \dagger \S$ \\
& SOL & $8 \pm 1$ & $13 \pm 1^{*}$ & $12 \pm 1^{*}$ & $14 \pm 2^{*}$ \\
$S V$ & NIS & $10 \pm 1$ & $15 \pm 1^{*}$ & $14 \pm 1^{*}$ & $13 \pm 1^{*} \S$ \\
& SOL & $25 \pm 2$ & $17 \pm 2^{*}$ & $18 \pm 2^{*}$ & $14 \pm 2^{*}$ \\
& NIS & $27 \pm 2$ & $18 \pm 2^{*}$ & $19 \pm 1^{*}$ & $16 \pm 2^{*}$ \\
$M W$ & SOL & $43 \pm 3$ & $48 \pm 4$ & $46 \pm 3$ & $58 \pm 10$ \\
& NIS & $38 \pm 2$ & $40 \pm 3$ & $37 \pm 2$ & $40 \pm 4$ \\
& SOL & $225 \pm 16$ & $121 \pm 16$ & $118 \pm 14^{*}$ & $69 \pm 14^{*}$ \\
& NIS & $222 \pm 18$ & $130 \pm 13$ & $124 \pm 11^{*}$ & $111 \pm 15^{*} \ddagger \S$ \\
\hline
\end{tabular}

Data are presented as means $\pm \mathrm{SE} ; \mathrm{N}=9$ for both groups; $\mathrm{SOL}=$ solvent-treated, $\mathrm{NIS}=$ nisoldipine-treated; $M A P=$ mean arterial blood pressure $(\mathrm{mmHg}) ; C O=\operatorname{cardiac}$ output $(\mathrm{L} / \mathrm{min})$; $H R=$ heart rate (beats $/ \mathrm{min}) ; L V \mathrm{~d} P / \mathrm{d} t_{\max }=$ maximum rise in left ventricular pressure $(\mathrm{mmHg} / \mathrm{sec}) ;$ $L V E D P=$ left ventricular end diastolic blood pressure $(\mathrm{mmHg}) ; S V$ - stroke volume $(\mathrm{mL}) ; S V R=$ systemic vascular resistance $(\mathrm{mmHg} /(\mathrm{L} / \mathrm{min})) ; M W=$ myocardial work $(\mathrm{mmHg} . \mathrm{L} / \mathrm{min})$.

* $P<0.05$ versus baseline:

† nisoldipine-induced changes versus baseline are significantly different from changes in the solvent-treated animals;

$\ddagger$ nisoldipine-induced changed versus $30 \mathrm{~min}$ of ischaemia are significantly different from changes in the solvent-treated animals;

$\S$ nisoldipine-induced changes versus $60 \mathrm{~min}$ of ischaemia are significantly different from changes in the solvent-treated animals.

further declined; the decrease versus baseline was, however, significantly smaller than in the solventtreated animals (Table 1). Mean arterial blood pressure did not further decrease and $L V \mathrm{~d} P / \mathrm{d} t_{\max }$ even increased $(P<0.05$ versus changes in solventtreated animals). Left ventricular end diastolic pressure decreased from $14 \pm 1$ to $13 \pm 1 \mathrm{mmHg}$, which was significantly different from the increase, observed in the solvent-treated animals. Heart rate was not affected and stroke volume decreased similarly as in the solvent-treated animals.

\section{Regional myocardial perfusion and myocardial oxygen consumption}

The microsphere data revealed that inflation of the balloon had caused similar decreases in transmural myocardial blood flow in the solventtreated (from $82 \pm 5 \mathrm{~mL} / \mathrm{min} / 100 \mathrm{~g}$ to $19 \pm 9 \mathrm{~mL}$ / $\mathrm{min} / 100 \mathrm{~g}$ ) and the nisoldipine-treated animals (from $87 \pm 12$ to $14 \pm 8 \mathrm{~mL} / \mathrm{min} / 100 \mathrm{~g}$, Fig. 1) during the first $30 \mathrm{~min}$ of ischaemia. There were no further changes in the solvent-treated animals during the following $30 \mathrm{~min}$ of LADCA stenosis (LADCA blood flow was $19 \pm 6 \mathrm{~mL} / \mathrm{min} / 100 \mathrm{~g}$ at $30 \mathrm{~min}$ of ischaemia). In the nisoldipine-treated animals myocardial blood flow increased from $14 \pm 8 \mathrm{~mL}$ / $\mathrm{min} / 100 \mathrm{~g}$ to $24 \pm 6 \mathrm{~mL} / \mathrm{min} / 100 \mathrm{~g}$. After $2 \mathrm{hr}$ of reperfusion transmural myocardial blood flow of the LADCA-perfused area had increased to $41 \pm 6 \mathrm{~mL}$ / $\mathrm{min} / 100 \mathrm{~g}$ and $76 \pm 14 \mathrm{~mL} / \mathrm{min} / 100 \mathrm{~g}$ in the solventtreated and the nisoldipine-treated animals, respectively $(\mathrm{P}<0.05$ versus $60 \mathrm{~min}$ of ischaemia; Fig. 1).
In both the solvent- and the nisoldipine-treated animals transmural blood flow to the non-ischaemic area decreased slightly during ischaemia, secondary to the fall in arterial blood pressure. However, during reperfusion, vasodilatation prevented perfusion decreasing parallel to the fall in perfusion pressure in the nisoldipine-treated but not in the solventtreated pigs.

Baseline values of myocardial oxygen consumption of the LADCA-perfused myocardium were $2.9 \pm 0.3 \mathrm{~mL} \mathrm{O}_{2} / \mathrm{min} / \mathrm{g}$ and $3.5 \pm 0.5 \mathrm{~mL} \mathrm{O}_{2} / \mathrm{min} / \mathrm{g}$ in the solvent-treated and the nisoldipine-treated animals, respectively. After $2 \mathrm{hr}$ of reperfusion these respective values were $0.56 \pm 0.06$ and $1.18 \pm 0.30 \mathrm{~mL} \mathrm{O}_{2} / \mathrm{min} / \mathrm{g}(\mathbf{P}>0.05)$.

\section{Regional myocardial wall function}

Reduction of coronary blood flow totally abolished systolic wall thickening of the segment perfused by the LADCA in both groups (baseline values in the nisoldipine-treated and the solvent-treated animals were $31 \pm 4 \%$ and $33 \pm 4 \%$, respectively), which did not change in either group neither during the remainder of the ischaemic episode nor during the reperfusion period. PSWT of the ischaemic myocardium after 30 and $60 \mathrm{~min}$ of ischaemia was $11 \pm 1 \%$ and $8 \pm 1 \%$ in the solvent-treated, and $10 \pm 2 \%$ and $10 \pm 2 \%$ in the nisoldipine-treated animals, respectively.

\section{High energy phosphates}

During ischaemia and reperfusion there were no 

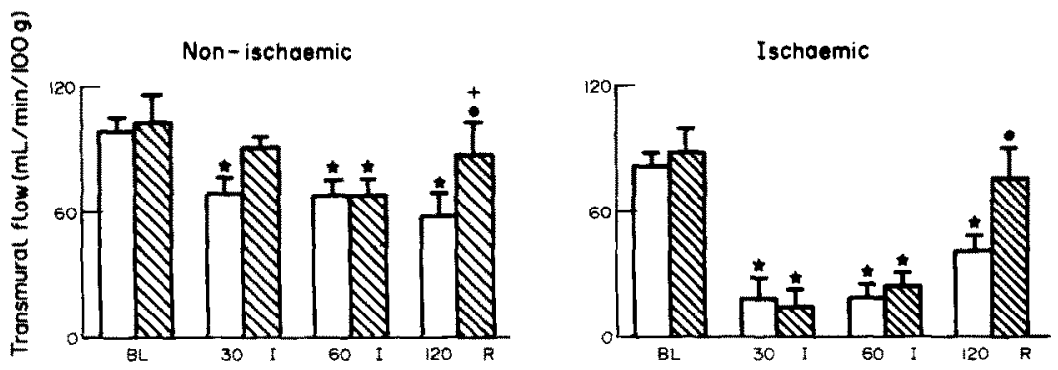

Fig. 1. Transmural myocardial blood flow $(\mathrm{mL} / \mathrm{min} / 100 \mathrm{~g})$ of non-ischaemic and ischaemic myocardium in solvent-treated (open bars, $\mathrm{N}=9$ ) and nisoldipine-treated (hatched bars, $\mathrm{N}=9$ ) pigs at baseline (BL), after 30 and $60 \mathrm{~min}$ of ischaemia (I), and $120 \mathrm{~min}$ of reperfusion (R). ( $\left.{ }^{*}\right) \mathrm{P}<0.05$ versus baseline, $(+)$ changes versus baseline in the nisoldipine-treated animals are significantly different from the changes versus baseline in the solvent-treated animals; $(\bullet)$ changes versus $60 \mathrm{~min}$ of ischaemia in the nisoldipine-treated animals are significantly different from the changes versus 60 min of ischaemia in the solvent-treated animals.
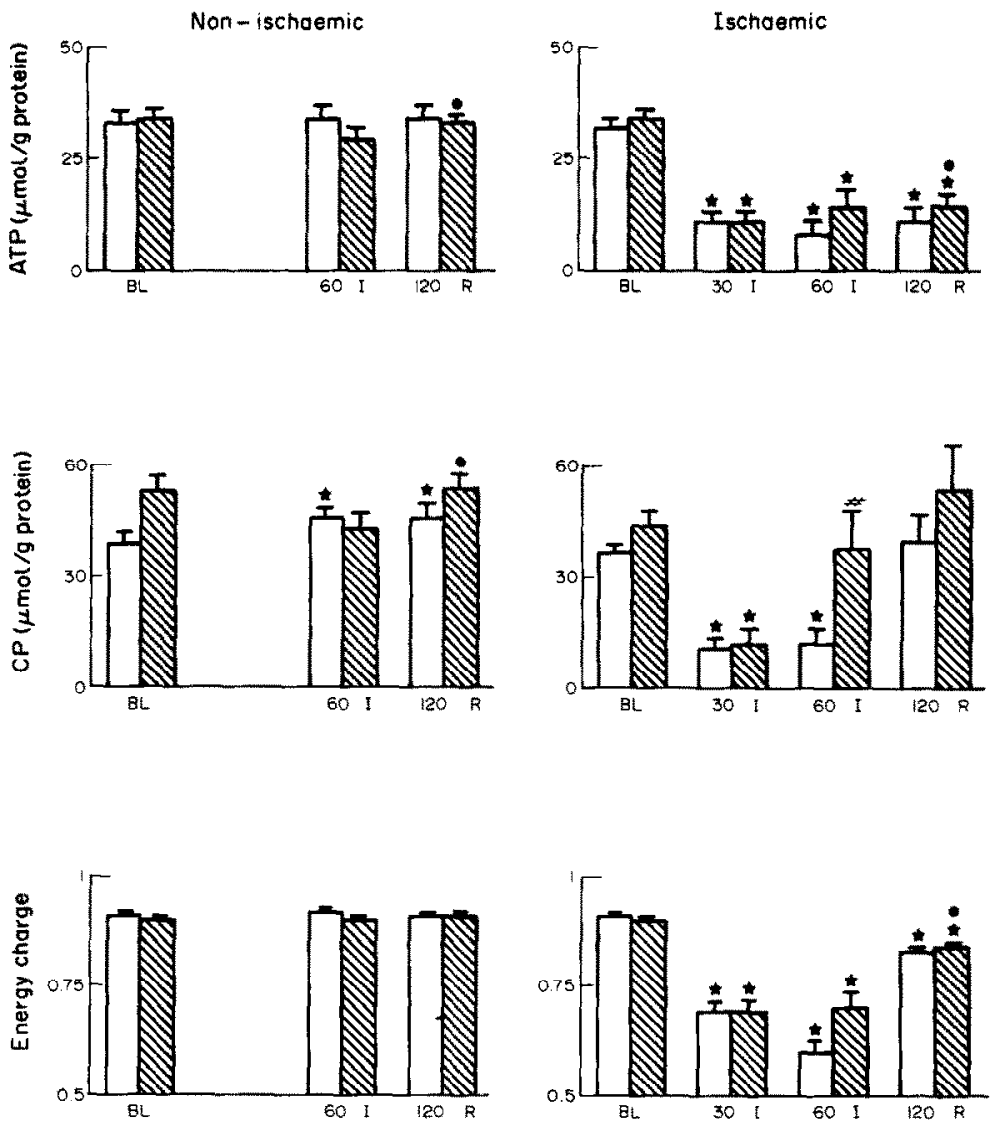

Fig. 2. ATP and CP ( $\mu \mathrm{mol} / \mathrm{g}$ protein) and energy charge $\left[\left(\mathrm{ATP}+\frac{1}{2} \mathrm{ADP}\right) /(\mathrm{ATP}+\mathrm{ADP}+\mathrm{AMP})\right]$ of the ischaemic and non-ischaemic myocardium of solvent-treated (open bars, $N=9$ ) and nisoldipinetreated pigs (hatched bars, $\mathrm{N}=9$ ) at baseline (BL), at $30 \mathrm{~min}$ (only for the ischaemic segment) and $60 \mathrm{~min}$ of ischaemia (I) and after $120 \mathrm{~min}$ of reperfusion (R). ( $\left.{ }^{*}\right) \mathrm{P}<0.05$ versus baseline; (\#) changes versus $30 \mathrm{~min}$ of ischaemia in the nisoldipine-treated animals are significantly different from changes versus $30 \mathrm{~min}$ of ischaemia in the solvent-treated animals; $(\bullet)$ changes versus $60 \mathrm{~min}$ of ischaemia in the nisoldipine-treated animals are significantly different from the changes versus $60 \mathrm{~min}$ of ischaemia in the solvent-treated animals.

changes in the levels of ATP, adenine nucleotides and the energy charge in the non-ischaemic myocardium of both the solvent- and the nisoldipinetreated animals (Figs 2 and 3). The concentrations of $\mathrm{CP}$ and total creatine decreased in the nisoldipinetreated animals while there was a slight increase in the solvent-treated animals ( $P<0.05$; Figs 2 and 3 ). After $2 \mathrm{hr}$ of reperfusion the differences between 

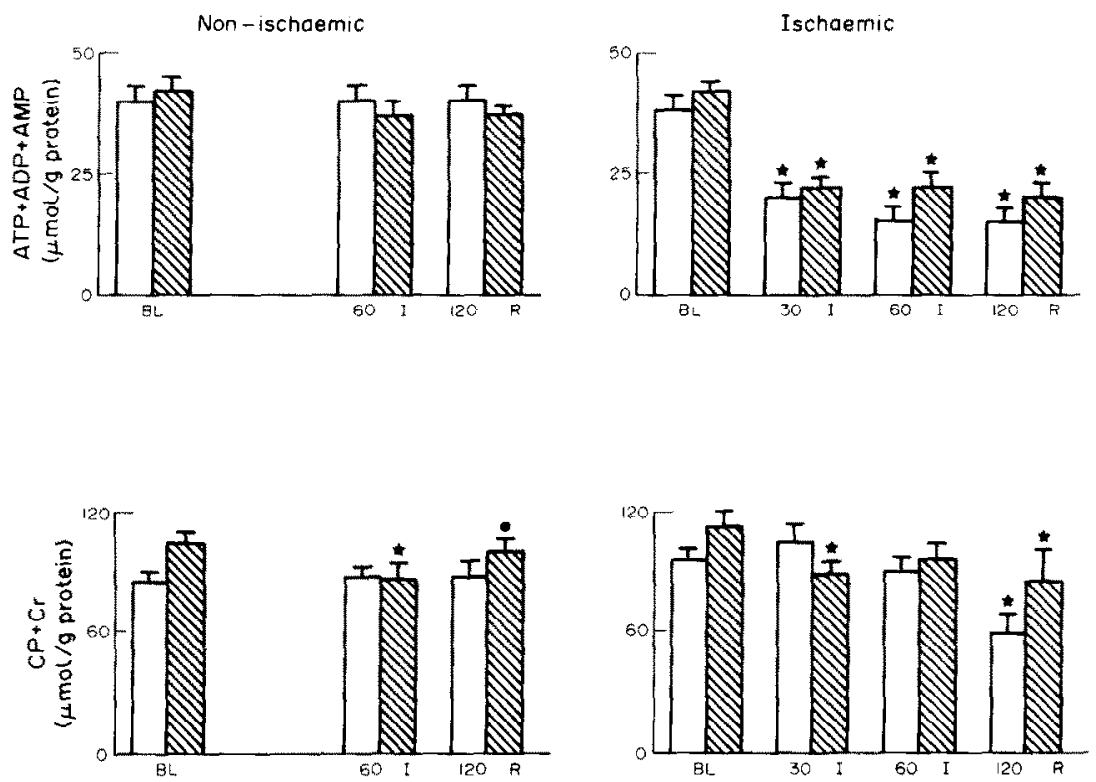

Fig. 3. Total adenine nuclentides $(A T P+A D P+A M P)$ and total creatine $(C P+$ creatine $)$ of the nonischaemic and ischaemic myocardium in solvent-treated (open bars, $\mathrm{N}=9$ ) and nisoldipine-treated (hatched bars, $\mathrm{N}=9$ ) pigs at baseline $(\mathrm{BL}$ ), at $30 \mathrm{~min}$ (only for the ischaemic segment) and $60 \mathrm{~min}$ of ischaemia (I) and after $120 \mathrm{~min}$ of reperfusion $(R) .\left(^{*}\right) \mathrm{P}<0.05$ versus baseline; $(\bullet)$ changes versus $60 \mathrm{~min}$ of ischaemia in the nisoldipine-treated animals are significantly different from the changes versus $60 \mathrm{~min}$ of ischaemia in the solvent-treated animals.

groups in concentrations of $\mathrm{CP}$ and total creatine were no longer present.

In the LADCA-perfused myocardium of the solvent- and the nisoldipine-treated animals $30 \mathrm{~min}$ of flow reduction caused decreases in ATP (by 66 and $68 \%$, respectively), $\mathrm{CP}$ (by 70 and $73 \%$, respectively) and total adenine nucleotides ( 47 and $48 \%$, respectively), while the energy charge decreased from $0.90 \pm 0.01$ and $0.91 \pm 0.01$ in the nisoldipine- and solvent-treated animals, respectively, to $0.69 \pm 0.04$ in both groups. During the following $30 \mathrm{~min}$ of ischaemia in the solvent- but not in the nisoldipine-treated animals the level of ATP and the energy charge further decreased. Furthermore, the increase in CP to $92 \pm 24 \%$ of baseline observed in the nisoldipine-treated animais was absent in the solvent-treated pigs. The total creatine pool showed no changes in the solventtreated animals during ischaemia, while a slight but significant decrease was observed in the nisoldipinetreated animals after $30 \mathrm{~min}$ of ischaemia. After $2 \mathrm{hr}$ of reperfusion no recovery of the levels of ATP and total adenine nucleotides was observed in either group, while those of $\mathrm{CP}$ were at baseline and the energy charge had recovered similarly in both groups to $0.83 \pm 0.03$. The level of total creatine remained 25 and $35 \%$ below baseline in the nisoldipine- and the solvent-treated animals, respectively.

\section{$\mathrm{Ca}^{2+}$ uptake and phospholamban phosphorylation}

$\mathrm{Ca}^{2+}$ uptake and in vitro phosphorylation of phospholamban could only be determined at the end of reperfusion because of the amount of myocardium $(5 \mathrm{~g})$, needed for the isolation of sufficient amounts of SR membrane vesicles. The rate of $\mathrm{Ca}^{2+}$ uptake of the non-ischaemic segment of the nisoldipinetreated animals was $61 \%$ higher $(P<0.05)$ than that of the solvent-treated animals, and phospholamban phosphorylation, on the other hand, was $33 \%$ lower $(\mathrm{P}<0.05)$. (Table 2) The rates of $\mathrm{Ca}^{2+}$ uptake of $S R$ vesicles isolated from post-ischaemic segments were not different: $531 \pm 94 \mathrm{nmol} / \mathrm{min} / \mathrm{mg}$ and $727 \pm 212 \mathrm{nmol} / \mathrm{min} / \mathrm{mg}$ in the solvent-treated and the nisoldipine-treated animals, respectively. The in vitro ${ }^{32} \mathrm{P}$ incorporation remained $43 \%$ lower in the nisoldipine-treated $(765 \pm 96 \mathrm{pmol} / \mathrm{mg}$ ) compared to the solvent-treated animals $(1336+263 \mathrm{pmol} /$ $\mathrm{mg}$ ).

\section{DISCUSSION}

The present study demonstrates that nisoldipine increased post-ischaemic myocardial blood flow. This could be due to a direct coronary vasodilatory action of the drug, since vascular resistance of the non-ischaemic myocardium decreased (from $0.91 \pm 0.09 \mathrm{mmHg} /(\mathrm{mL} / \mathrm{min} / 100 \mathrm{~g}$ ) to $0.74 \pm 0.10 \mathrm{mmHg} /(\mathrm{mL} / \mathrm{min} / 100 \mathrm{~g}) \quad(\mathrm{P}<0.05$ versus baseline) in the nisoldipine-treated animals, whereas there was no change in the solvent-treated animals (baseline $1.02 \mathrm{mmHg} /(\mathrm{mL} / \mathrm{min} / 100 \mathrm{~g})$ ). However, the higher myocardial oxygen demand reflected by the higher double-product (heart rate times systolic arterial pressure) in the nisoldipinetreated animals $\left(94 \times 10^{2} \pm 11 \times 10^{2} \mathrm{mmHg}\right.$.beats/ min versus $71 \times 10^{2} \pm 11 \times 10^{2} \mathrm{mmHg}$.beats $/ \mathrm{min}$ in the solvent-treated pigs) also contributes to the 
Table 2. Effect of nisoldipine or its solvent on $\mathrm{Ca}^{2+}$ uptake and in vitro ${ }^{32} \mathrm{P}$ incorporation into phospholamban of sarcoplasmic reticulum isolated from post-ischaemic myocardium in open-chest anaesthetized pigs

\begin{tabular}{llcc}
\hline & $\begin{array}{c}\mathrm{Ca}^{2+} \text {-uptake } \\
(\mathrm{nmol} / \mathrm{min} / \mathrm{mg})\end{array}$ & $\begin{array}{c}{ }^{32} \mathrm{P} \text { incorporation } \\
(\mathrm{pmol} / \mathrm{mg})\end{array}$ \\
\hline Non-ischaemic myocardium & SOL & $830 \pm 117$ & $1605 \pm 170$ \\
Post-ischaemic myocardium & NIS & $1335 \pm 107^{*}$ & $1083 \pm 48^{*}$ \\
& SOL & $531 \pm 94$ & $1336 \pm 263$ \\
& NIS & $727 \pm 212$ & $765 \pm 96^{*}$
\end{tabular}

Data are presented as means $\pm \mathrm{SE} ; \mathrm{SOL}=$ solvent-treated $(\mathrm{N}=7)$; NIS $=$ nisoldipinetreated $(\mathbf{N}=9)$.

${ }^{*} \mathrm{P}<0.05$ versus solvent-treated animals.

vasodilatation of the coronary bed of the nonischaemic myocardium.

The failure of tissue to reperfuse after a transient ischaemic period has been called the no-reflow phenomenon. The higher blood flow in the postischaemic myocardium in the nisoldipine-treated animals could also be secondary to attenuation of this phenomenon by nisoldipine. The mechanisms by which nisoldipine can preserve cardiomyocytes and endothelial cells are diverse. Takahashi and Kako [21] demonstrated that nisoldipine was capable of suppressing the ischaemia-induced increase in phospholipid breakdown of canine cardiac sarcolemma. It has also been shown that nisoldipine decreased transcoronary extravasation [12] and the authors postulated that secondary to a reduction in $\mathrm{Ca}^{2+}$ uptake during reperfusion, nisoldipine prevented endothelial deformation and formation of interendothelial gaps. We found that nisoldipine caused a significant increase in CP already during ischaemia. The further decreases in the level of ATP and the energy charge, as observed in the salinetreated animals during the last $30 \mathrm{~min}$ of ischaemia, were prevented in the nisoldipine-treated pigs, albeit that these differences were not significant. Nevertheless, since the increase in CP must be a consequence of a more rapid rephosphorylation of ADP, the energy metabolism in the nisoldipinetreated animals during ischaemia must have been more favourable. This might have led to preservation of jeopardized cells contributing to the maintenance of the microvascular integrity.

Recently, Gross et al. [22] investigated the effect of the dihydropyridine amlodipine on subendocardial segment length shortening, regional blood flow and myocardial high energy phosphate levels in coronary ligated ( $45 \mathrm{~min}$ of total occlusion) dogs followed by $2 \mathrm{hr}$ of reperfusion). LADCA blood flow during ischaemia and systemic haemodynamics in that study were similar as those in the present study. However, at variance with the present study, Gross et al. [22] observed a marked and sustained improvement in systolic wall function at the end of the reperfusion period. The authors postulated that a positive inotropic action, as also observed for the $\mathrm{Ca}^{2+}$ antagonist felodipine [23], might have reversed myocardial stunning, thereby attenuating the rebound in $\mathrm{CP}$.

In the present study the higher post-ischaemic blood flow in the nisoldipine-treated animals was not accompanied by a return of systolic contractile function during early reperfusion. The explanation for this can be four-fold. Firstly, a negative inotropic action of the drug prevented return of function. This is highly unlikely as in pigs this dose of nisoldipine does not cause negative inotropy [24]. Secondly, the myocardial tissue is irreversibly injured. GarciaDorado et al. [25] have shown (by tetrazoliumstaining) that in pigs $30-40 \%$ of the myocardium at risk was still viable after $1 \mathrm{hr}$ of total coronary artery occlusion. In the present study we reduced coronary blood flow to $15-20 \%$ of baseline during the $60 \mathrm{~min}$ of ischaemia and a significant fraction of the affected myocardium must therefore ultimately (even after days) recover in function. Thirdly, the low energy charge of the post-ischaemic myocardium prevented contractile function. However, it has repeatedly been demonstrated that enhanced recovery of function occurs while the ATP-levels are still low [26-28]. Finally, Krause et al. [29] have suggested that the inability of the stunned myocardium to function normally is due to a slight reduction of the activity of the $\mathrm{Ca}^{2+}$ pump.

$\mathrm{Ca}^{2+}$-uptake in the non-ischaemic myocardium of the nisoldipine-treated pigs was higher than that of the solvent-treated animals. Two possible mechanisms of action can be forwarded: (i) a direct stimulation of the pump by nisoldipine is involved since it has been demonstrated that dihydropyridines stimulate $\mathrm{Ca}^{2+}$ uptake of canine cardiac sarcoplasmic reticulum [7] and interestingly also of porcine cardiac sarcolemma [30]. However, this mechanism of action may be expected to be masked by the $S R$ isolation procedure, during which drugs are removed from their target proteins or phospholipids. On the other hand, the lipophilic nature of the dihydropyridines [31] may have retarded their removal from the phospholipid bilayer; (ii) the activation of the $\mathrm{Ca}^{2+}$ pump is secondary to a $\beta$-adrenoceptor-mediated mechanism. In the nisoldipine-treated animals the $L V \mathrm{~d} P / \mathrm{d} t_{\max }$ was significantly increased and there was a tendency for the heart rate to increase, both suggesting a higher level of $\beta$-adrenoceptor activity. The nisoldipine-induced decrease in in vitro ${ }^{32} \mathrm{P}$ incorporation of phospholamban, found in the nonischaemic myocardium, is in agreement with an increased $\beta$-adrenoceptor activity causing an in vivo phosphorylation of the protein, although rapid 
dephosphorylation of sarcolemmal phospholamban has been shown to occur during the homogenization and fractionation of the myocardial tissue needed for isolation of the membrane vesicles [18]. Therefore, to definitely prove that the increase of $\mathrm{Ca}^{2+}$ uptake rate and decrease of in vitro ${ }^{32} \mathrm{P}$ incorporation in myocardium by nisoldipine is due to increased $\beta$-adrenoceptor activity, the degree of phosphorylation of phospholamban should be measured in vivo. We have no explanation for the lack of a significant increase of $\mathrm{Ca}^{2+}$ uptake by nisoldipine in the ischaemic myocardium.

A lower in vitro ${ }^{32} \mathrm{P}$ incorporation into phospholamban in ischaemic myocardium has been associated with a modification of the structure or membrane component of the protein $[3,18,32]$. Evidence has been obtained that the reduction in sarcoplasmic reticulum $\mathrm{Ca}^{2+}$ pump is causally related with the modified properties of phospholamban [3]. We found a reduced $\mathrm{Ca}^{2+}$ uptake and in vitro ${ }^{32} \mathrm{p}$ incorporation into phospholamban of the ischaemic segments of both the solvent- and the nisoldipinetreated animals. However, the effects of nisoldipine on $\mathrm{Ca}^{2+}$ uptake and in vitro ${ }^{32} \mathrm{P}$-incorporation into phospholamban observed in the ischaemic myocardium tend to be similar to those in the nonischaemic myocardium. Therefore, the interpretation of the nisoldipine-induced effects on SR function during ischaemia-reperfusion are complicated by a possible direct or $\beta$-adrenoceptor-mediated action of the drug.

\section{REFERENCES}

1. Opie LH, Reperfusion injury and its pharmacologic modification. Circulation 80: 1049-1063, 1989.

2. Jennings RB, Reimer $\mathrm{KA}$ and Steenbergen $\mathrm{C}$, Myocardial ischemia revisited. The osmolar load, membrane damage, and reperfusion. $J$ Mol Cell Cardiol 18: $769-780,1986$.

3. Schoutsen B, Blom JJ, Verdouw PD and Lamers JMJ, Calcium transport and phospholamban in sarcoplasmic reticulum of ischemic myocardium. $\mathrm{J} \mathrm{Mol}$ Cell Cardiol 21: 719-727, 1989.

4. Chemnitius JM, Sasaki Y, Burger W and Bing RJ, The effect of ischemia and reperfusion on sarcolemmal function in perfused canine hearts. $J$ Mol Cell Cardiol 17: $1139-1150,1985$.

5. Godfraind $T$, Miller $R$ and Wibo $M$, Calcium antagonism and calcium entry blockade. Pharmacol Rev 86: 321-416, 1986.

6. Ferrari R, Curello AA, Ceconi C, Dilisa F, Raddino $R$ and Visioli $O$. Myocardial recovery during postischaemic reperfusion: effects of nifedipine, calcium and magnesium. J Mol Cell Cardiol 18: 487-498, 1986.

7. Movsesian MA, Ambudkar IS, Adelstein RS and Shamoo AE, Stimulation of canine cardiac sarcoplasmic reticulum $\mathrm{Ca}^{2+}$ uptake by dihydropyridine $\mathrm{Ca}^{2+}$ antagonists. Biochem Pharmacol 34: 195-201, 1985.

8. Tada $M$ and Katz AM, Phosphorylation of the sarcoplasmic reticulum and sarcolemma. Annu Rev Physiol 44: 401-423, 1982.

9. Lamers JMJ and Weeda E, Methods for studying phosphorylation in the heart membranes. In: Methods in Studying Cardiac Membranes (Ed. Dhalla NS), Vol. 1, pp. 179-202. CRC Press, Boca Raton, FL, 1984.

10. Lindeman JP and Watanabe AM, Phosphorylation of phospholamban in intact myocardium. I Bial Chem 260: $4516-4525,1985$.
11. Nigdikar SV and Bowditch Dow JW, Calcium antagonists and adenine nucleotide metabolism in rat heart. Cardiovasc Res 20: 604-608, 1986.

12. McDonagh PF and Roberts DJ, Prevention of transcoronary macromolecular leakage after ischemiareperfusion by the calcium entry blocker nisoldipine. Circ Res 58: 127-136, 1986.

13. Daly MJ, Elz JS and Nayler WG, The effect of verapamil on ischaemia-induced changes to the sarcolemma. J Mol Cell Cardiol 17: 667-674, 1985.

14. Nayler WG, Ferrari R and Williams A. Protective effect of pretreatment with verapamil, nifedipine and propranolol on mitochondrial function in the ischemic and reperfused myocardium. Am I Cardiol 46: 242$248,1980$.

15. Saxena PR, Schamhardt HC, Forsyth RP and Loeve $\mathrm{J}$. Computer programs for the radioactive microsphere technique. Determination of regional blood flows and other haemodynamic variables in different experimental circumstances. Comp Progr Biomed 12: 63-84, 1980.

16. Saxena PR and Verdouw PD, Redistribution by 5 . hydroxytryptamine of carotid arterial blood at the expense of arteriovenous anastomotic blood flow. $y$ Physiol 332: 501-520, 1982.

17. Sellevold OFM, Jynge $P$ and Aarstad K, High performance liquid chromatography: a rapid isocratic method for determination of creatine compounds and adenine nucleotides in myocardial tissue. $\mathrm{J} \mathrm{Mol} \mathrm{Cell}$ Cardiol 18: $517-527,1986$.

18. Lamers JMJ, De Jonge-Stinis JT, Hülsmann WC and Verdouw PD, Reduced in vitro ${ }^{32} \mathrm{P}$ incorporation into phospholamban-like protein of sarcolemma due to myocardial ischaemia in anaesthetized pigs. $J \mathrm{Mol}$ Cell Cardiol 18: 115-125, 1986.

19. Lowry OH, Rosenbrough NJ, Farr AL and Randall RJ, Protein measurement with the Folin phenol reagent. J Biol Chem 193: 265-275, 1951.

20. Bradford MM, A rapid and sensitive method for the quantitation of microgram quantities of protein utilizing the principle of protein-dye binding. Anal Biochem 72: $248-254,1976$

21. Takahashi $\mathrm{K}$ and Kako $\mathrm{KJ}$, The effect of a calcium channel antagonist, Nisoldipine, on the ischemiainduced change of canine sarcolemmal membrane. Bas Res Cardiol 78: 326-337, 1983.

22. Gross GJ, Farber NE and Pieper GM, Effect of amlodipine on myocardial functional and metabolic recovery following coronary occlusion and reperfusion in dogs. Cardiovasc Drugs Ther 3: 535-543, 1989.

23. Drake-Holland AJ, Pugh S, Noble NIM and Mills $C$, Problem of measuring the positive inotropic property of a vasodilating drug; an illustration using felodipine. Cardiovasc Res 21: 631-636, 1987.

24. Duncker DJ, Hartog JM, Hugenholtz PG, Saxena PR and Verdouw PD, The effects of nisoldipine (Bay K 5552) on cardiovascular performance and regional blood flow in pentobarbital-anaesthetized pigs with or without $\beta$-adrenoceptor blockade. BrJ Pharmacol 88: $9-18,1986$.

25. Garcia-Dorado D. Theroux P. Elizaga J, Galinanes M, Solares J, Riesgo M, Gomez MJ, Garcia-Dorado A and Avilles FF, Myocardial reperfusion in the pig heart model: infarct size and duration of coronary occlusion. Cardiovasc Res 21: 537-544, 1987.

26. Arnold JMO, Braunwald E. Sandor T and Kloner RA, Inotropic stimulation of reperfused myocardium with dopamine: effects on infarct size and myocardial function. J Am Coll Cardiol 6: 1026-1034, 1985.

27. Van der Giessen WJ, Schoutsen B, Tijssen JGP and Verdouw PD, Iloprost (ZK 36374) enhances recovery of regional myocardial function during reperfusion after coronary artery occlusion in the pig. $\mathrm{Br} J$ Pharmacol 87: 23-27, 1986. 
28. Farber NE, Pieper GM, Thomas JP and Gross GJ, Beneficial effects of iloprost in the stunned canine myocardium. Circ Res 62: 204-215, 1988.

29. Krause SM, Jacobus WE and Becker LC, Alteration in cardiac sarcoplasmic reticulum calcium transport in the post-ischemic "stunned myocardium". Circ Res 61: 526-530, 1989

30. Lamers JMJ, Cysouw $\mathrm{KJ}$ and Verdouw PD, Slow calcium channel blockers and calmodulin: effect of felodipine, nifedipine, prenylamine and bepredil on cardiac sarcolemmal calcium pumping ATPase. Biochem Pharmacol 34: 3837-3843, 1985.
31. Herbette LG, Techniques for determining membrane structure: the necessity for understanding cardiovascular drug-membrane interactions at the molecular level. In: The Heart and Cardiovascular System (Eds. Fozzard HA, Haber E, Jennings RB, Katz AM and Morgan HE), pp. 263-289. Raven Press, New York, 1986.

32. Van der Giessen WJ, Verdouw PD, Cate ten FJ, Essed $\mathrm{CE}$, Rijsterborgh $\mathrm{H}$ and Lamers $\mathrm{JMJ}$, In vitro cyclic AMP induced phosphorylation of phospholamban: an early marker of long-term recovery of function following reperfusion of ischaemic myocardium? Bas Res Cardiol 10: 714-718, 1988. 